\title{
Academic Freedom and Educational Responsibility in Malaysian Higher Institutions of Learning
}

\section{Che Noraini Hashima, Syed Marwan Mujahid Syed Azman ${ }^{b}$, Sharifah Nur Asmaa' Syed Azmanc}

\begin{abstract}
New challenges of academic freedom and educational responsibility in Malaysian higher institutions of learning had been of great concern to all parties alike. However, academic freedom needs to be accompanied by educational responsibility. In Malaysia, serious research regarding academic freedom and academic responsibility, is yet to be undertaken. This paper identifies the relationship between academic freedom and educational responsibility; highlights major challenges faced by academicians in exercising academic freedom, and analyses responses from academicians. In addition, the paper suggests some improvements to the current practices of academic freedom in Malaysian higher institutions of learning. A semi-structured interview schedule was designed to gain insight on academic freedom and educational responsibility from randomly selected senior academicians attached to three Malaysian universities. Findings show that there exists a strong positive relationship between academic freedom and educational responsibility. Respondents also perceived that the regulations and restrictions imposed upon academicians did not act as obstacles to voice opinions, if the regulations and restrictions were taken positively and are used as measures to exercise academic responsibility. Their perceptions suggest that the main challenge faced by academicians comes, perhaps, from their own fears and inhibitions. The prognosis is that academic freedom in Malaysian universities
\end{abstract}

a Associate Professor, Kulliyyah of Education, International Islamic University Malaysia, email: cnoraini@gmail.com

b PhD student, Institute of Islamic Banking and Finance (IIBF), International Islamic University Malaysia

c Student of Ahmad Ibrahim Kulliyah of Laws (AIKOL), International Islamic University Malaysia 
can be realized by students and academicians alike, if they express their views within certain limitations; but the society and the government should be more tolerant and be receptive to constructive criticism.

Keywords: Academic freedom, Educational responsibility, Malaysia Higher Institution of Learnings.

\section{Introduction}

Academic freedom and educational responsibility have long been a topic of public concern in many developing nations, including Malaysia. New challenges and concerns regarding academic freedom and educational responsibility have not only affected government authorities but also the political parties. The higher institutions of learning (HIL) should be encouraging academicians and students to freely voice their opinions in order to benefit the society at large. As Matthew and Robert (2009) stressed, the importance of academic freedom is that "students cannot learn how to exercise mature independence of mind unless their instructors are themselves free to model independent thought in the classroom" (p.72). Thus in carrying out their educational responsibility, academicians should be given some academic liberty for the purpose of training their students to critically analyse opinions based on different perspectives. Furthermore, in the course of teaching and learning, both academicians and students should be able to openly discuss, criticise and evaluate facts and evidences.

Although there has been an increasing awareness of academic freedom among Malaysian academicians and society in general, relevant research literature focusing on the Malaysian context is rather limited. As such, much of the literature discussed in this paper are from countries such as the United States of America, the United Kingdom and Germany. The Association of American Colleges and Universities (AAC\&U) (2006) emphasizes that "freedom to explore significant and controversial questions is an essential precondition to fulfil the academy's mission of educating students and advancing knowledge" (p.19). The Association also requires professors to submit their knowledge and claims to rigorous and public review by peers who are experts in the subject matter under consideration; to ground their arguments in the best available evidence; and to work together to foster the education of students (p.20). 
The above statements clearly convey the justification for academic freedom and educational responsibility. Meanwhile Shils (1995) contended that academic freedom "... protects the moral and intellectual integrity of the teachers" (p.7). It follows then, that academic freedom empowers academicians not just within the classroom wall, but outside as well. Academicians are supposed to be given freedom to profess their opinions especially within their fields. This will motivate them to explore more and at the same time enhance their moral and intellectual integrity. Interestingly, Turner (1998) made a comparison between the role academic freedom plays for academics with the role that judicial independence plays for judges, or the role of clinical judgment for the medical practitioner. Likewise, White (2000) argues in a wider perspective that the concept of academic freedom is "not simply the right of professors to speak without fear or favour, but the atmosphere of consent that surrounds the whole process of research and instruction" (p. 60). This clearly shows that academic freedom is the basic pillar of the academic profession as it is vital in the course of educating students.

Generally, academicians (including teachers) are supposed to be allowed to give opinions or suggestions within their knowledge specialisations; but the newly implemented Malaysian School Based Assessement (SBA) policy introduced by the Ministry of Education has created problems for teachers (Che Noraini 2013). However, the majority of teachers are hesitant to voice their dissatisfaction. This may be due to their lack of understanding of the specifications in their terms of appointment; or it may be due to teachers' academic culture in Malaysia - namely, to accept and comply with any policy imposed on them without question.

In the Malaysian context, Manan (2000) discusses the relationship between academic freedom, educational responsibility and university authority; he strongly believes that academic freedom is the conscience of the university, which affects the rights and responsibilities of lecturers and students, and colours the nature of teaching and scholarship. In addition, it cannot be denied that academic freedom, educational responsibility and university autonomy are closely linked. He is sceptical as to the existence of basic academic freedom in Malaysia, since there are various restrictions imposed on members of the academia through laws such as the Universities and Universities Colleges Act (UUCA) and Statutory Bodies Act. It is quite apparent that there are some obstacles 
to exercising academic freedom in Malaysia. Kim-Hui and Wai-Mun (2008), made comparisons between Germany and Malaysia with regard to academic freedom. They pointed out that the lack of an academic and thinking culture is, indeed, a major challenge to Malaysian academia in the 21 st century. They listed the following elements contributing to the demise of Malaysian academia: the death of dialectic, the surrender of culture to technology, the slavery of market-driven education, administrators' hegemony, the syndrome of pseudo-professors, the bandwagon culture and wholesale purchase of ISO in education.

This review of literature reveals that the rationale for academic freedom and educational responsibility in the United Kingdom, the United States, Germany and Malaysia are similar. However, in most cases it is the higher authority in the universities that control/restrict or encourage academic freedom among academicians, administrative staff and students. In the literature, it was found that some researchers prefer a more liberal approach to academic freedom, while some opt for the more restrictive interpretation. One cannot therefore ignore the fact that academic freedom and academic responsibility are inter-related and important in order to produce a better quality of academicians and students. Thus, just and fair academic freedom should be allowed in higher institutions of learning in Malaysia and it should be responsive to the needs of the society as a whole.

\section{Objectives of the study}

The objectives of this study are as follows: Firstly, to identify the relationship between academic freedom and educational responsibility; secondly, to highlight major challenges faced by academicians in exercising academic freedom; thirdly, to analyse responses from academicians when dealing with challenges in exercising academic freedom; finally, to offer some suggestions on how to improve current practices of academic freedom in Malaysian HIL. The objectives of this study are addressed by the following research questions:

1. What is the relationship between academic freedom and educational responsibility?

2. What are the challenges faced by academicians in exercising their academic freedom?

3. How do academicians respond to the challenges to their academic freedom? 
4. What measures could be suggested to improve the current practices of academic freedom Malaysian HIL?

\section{Methodology}

In order to answer the above research questions and to achieve the objectives of this study, a semi-structured interview schedule was designed to seek responses from senior academicians from three different Malaysian universities. All of them are professors (professor A is a law lecturer, professor $\mathrm{B}$ is an economics lecturer and professor $\mathrm{C}$ is an English lecturer) who had more than 20 years of teaching experience. Before the interview took place, consent was secured to record the interviews. The interviews were then conducted face-to-face, in order to enhance a better flow of information and discussion, and to clarify vague answers, if any.

Each interview session was conducted in a casual and relaxed atmosphere, and took about one-and-a-half hours. An iPod Touch was employed to record the interviews, and the recorded data and information were transcribed and analysed for the purpose of answering the research questions and to meet the objectives set for this study. For ethical purposes, the respondents were assured of their anonymity.

\section{Findings and Discussions}

\section{General understanding of Academic Freedom}

Initially, all respondents shared similar ideas in that academic freedom, in general, is an important aspect that enables academicians to express their views or opinions in their writings, talks and lectures. Generally they support the idea of "Bring Back Democracy to Campuses", and they also support the Court of Appeal's declaration that it is unconstitutional of the Universities and University Colleges Act (UUCA 1971) to restrict students from expressing support for or opposition to a political party. In a landmark 2-1 majority decision, the three-person panel held that Section 15 (5)(a) of the UUCA is unreasonable and violates freedom of speech (The Sun, November 01, 2011, p 01).

If academic freedom is denied, it will likely discourage academicians from exploring new knowledge and carrying out their work effectively. The respondents also agreed that academicians must be able to come out with new and useful ideas which benefit their students and the public 
at large. As such, academicians should be given certain freedoms, i.e. freedom to express or publish new ideas without fear. They stressed that the main idea of being an academician is actually to explore, discuss and share new knowledge. However, this freedom must be exercised and safeguarded by some ethical values so that people could benefit from new and innovative ideas produced by academicians.

\section{The relationship between academic freedom and educational responsibility}

In answering the first research question, on the relationship between academic freedom and educational responsibility, all respondents acknowledged that as academicians, they hold responsibility to make sure that students were given not just any knowledge, but advanced, contemporary scholarship. To avoid regurgitating outdated information, academicians ought to explore new issues of both the know-what and the know-how, and especially the know-why. They also stated that academic freedom and educational responsibility must be well-balanced, in the sense that all regulations at the university and national levels would have to be observed while articulating their academic freedom.. One of the respondents further explained that "in balancing academic freedom and educational responsibility, the challenge is greater as a law professor as the various social, economic or political developments and issues are always associated with the law." Respondent A stressed that academicians at the Faculty of Law hold greater educational responsibility whereby they must be knowledgeable and well-equipped before giving criticism or comments for the benefit of all, especially in the context of legal matters. For example, when lawyers or judges 'did not seem to pass lawful judgement', academicians from the Faculty of Law must be cognisant of the possibility of a wrongful judgement and express their views publicly (without fear of reprisal) so as to put matters on a correct perspective.

With regard to the purpose of academic freedom, all respondents viewed it as important in expanding, widening and broadening insights and cognitions. Again, here, the respondents stressed that academic freedom ought to be exercised with caution, being careful not to trample on sensitive issues. Respondent A added that academic freedom was also perceived as a necessary condition for the intellectual growth of 
academicians, and the seedbed for nurturing students, in the course of educating them.

When asked if there was any Malaysian university that exercises full academic freedom, two respondents ( professors A and B) answered with a crisp "no". They supported their contention with the observation that, whether rules should be interpreted liberally or restrictively, usually would depend on who is governing the university, i.e. the Vice Chancellor (VC) or the directive imposed on the Vice Chancellor / Rector. The respondents gave a scenario whereby if the Rector is a rather futuristic and open-minded person, he or she would allow the academicians to say whatever they feel is right, but they must take responsibility for their utterances.

In comparing academic freedom in Malaysia with that in Western countries, two of the respondents contended that in Western countries where the issue of human rights is much more debated and liberally applied, they can write and voice their opinions almost without limit. In contrast, such acts are not allowed in Malaysia. Even when freedom is given, people should not ridicule any religious institutions. The two respondents consistently mentioned that there is a need to observe the guidelines and restrictions, so as not to create ill feelings or any bad consequences in the society.

A further question was asked about how academic freedom protects academicians. All respondents stated that academic freedom protects the interest of academicians in expressing themselves freely. Only with academic freedom can academicians progress and fully employ their intellect and experience. Otherwise they would keep repeating previous studies in the course of carrying out their educational responsibility to the students.

The challenges faced by academicians in exercising their academic freedom

This section addresses the second research question which deals with challenges faced by academicians in exercising their academic freedom. Regarding academic freedom in Malaysia, two of the respondents (professors B and C) agreed that in Malaysia, academicians were given academic freedom with some restrictions. They shared the view that, should these restrictions be taken positively, there shouldn't be any 
problem to regulate them. However, one of the respondents (Professor A) did not agree that academicians in Malaysian universities enjoy academic freedom. He cited one controversial and well-publicised issue, namely, the suspension of an academician from the International Islamic University (IIUM), Prof. Dr. Abdul Aziz Bari, who expressed his views on the Sultan of Selangor's intervention in a controversial raid by Islamic religious officials on a Christian church. Respondent A elaborated that there were diverse opinions among academicians, leaders, students and the society. He labeled the issue 'as an infringement on a lecturer's academic freedom'. He stressed that "this is a real challenge...even the ordinary public have more freedom than academicians in voicing out their opinions".

Professor C, on the contrary, was of the view that Prof. Dr. Abdul Aziz Bari had in fact abused his academic freedom. Respondent $\mathrm{C}$ admitted that, consequently, this case drew public attention to the issue as to whether or not the academic freedom truly exists in Malaysia. In this regard, respondent $\mathrm{C}$ also argued that if the regulations and restrictions were taken positively, they would not have been viewed as obstacles to academic freedom. Interestingly, respondent B contended that the biggest challenge that academicians face is actually the problem that comes from their inner selves. Academicians were too complacent in their own comfort zone, they don't strive to be more than they are. "Sometimes, it is not entirely the fault of those in authority, if the academicians stay silence," said respondent A. He further argued that "teachers at school and HIL academic staff are also to blame, in that some of them are more interested in accepting the academic administrative positions solely for the financial gain, rather than struggling to achieve true academic freedom or new ideas to be heard."

Respondent $\mathrm{C}$ also shared a similar view: "some academicians refuse to push themselves forward dynamically and progressively to search for new knowledge or give new suggestions/comments. Moreover, some academicians are too preoccupied with their outside jobs i.e. business or consultations, and it leaves them with no time to explore new knowledge or put forward their dissatisfaction to be heard."

In carrying out their educational responsibility to educate their students "... some academicians also choose to behave in a neutral 
manner, i.e. not to favour any particular political views or support any Non governmental Organization (NGOs).

Responses to the challenges to academic freedom and some suggestions

To answer the third research question, the researcher explained how with the presence of the challenges, the academicians could fully exercise the freedom to ensure the intellectual development of their students. Again, all of the respondents reiterated that carrying the educational responsibility wouldn't be a problem if more effort were made in the search for new knowledge. The educational responsibility is wide ranging, as it does not involve classroom teaching only. Academicians must be able to multitask, i.e. write their opinions and expose the students to newly found information. Respondent $\mathrm{C}$ replied that it is high time that academicians open up their horizons and see the information and knowledge in fresh new perspectives, and not by being passive to the current issues. However, Respondent B argued that if academicians were given full freedom of expression, including freedom to express their political inclination, it would distract students from their studies and exams. In contrast, respondent A disagreed with respondent B that expressing their political inclination would distract students from their studies and exams. He justified his argument by citing the use of modern media technology whereby social network sites could draw attention to situations of concern and academic freedom could easily be exercised, and it could also enhance efforts to encourage and protect academic freedom.

Lastly, in answering the fourth research question, the respondents offered some suggestions on how to improve the current practice of academic freedom in Malaysia. Firstly, to increase awareness of the importance of academic freedom among teachers, students and the academicians at HIL and society at large. Secondly, academicians have to be encouraged to explore new knowledge and be free to speak up their minds. The third point is on the interpretation of the said issues and knowledge which should be exercised professionally. Interpreting academic freedom liberally or restrictively plays a huge role in determining how the academicians carry out their educational responsibility. Thus the manner of interpreting it has to be clear so that no misunderstanding occurs in exercising academic freedom in 
the course of carrying out the educational responsibility. In order to improve on the practice of academic freedom in Malaysia, development of the society to becoming more receptive and open towards comments and critiques is very crucial; otherwise, academic freedom in Malaysia will remain stagnant.

\section{Conclusion}

This study has concluded that there exists a strong positive relationship between academic freedom and educational responsibility, but they should exist in a balanced atmosphere. The issue relating to whether or not academic freedom should be interpreted restrictively or liberally all depends on the highest authority of the university, i.e. the ViceChancellor or the Rector. Looking at the challenges, there are three main challenges likely to be faced by academicians, namely the presence of the statutory laws, e.g. the UUC \& Statutory Body, inner-self conflict, and off-campus pecuniary commitments. To face the challenges, the first thing that has to be decided is the way academic freedom is interpreted-liberally or restrictively. It is high time for a paradigm shift among teachers and academicians at HIL, to realise that they are capable of becoming agents of change on behalf of the society and the nation. Academicians must be willing to step out of their comfort zone and be bold enough to express their opinions. Individuals and students need to foster and promote their own intellectual capacity. The society also has to be trained to be more tolerant and receptive to comments and criticisms so that the current practices of academic freedom in Malaysia would improve. Young minds must be allowed to be free to find new ideas and methods to remedy illnesses and shortcomings in the society.

This study only focuses on academic freedom, educational responsibility and challenges faced by HIL academicians and only three identified professors were interviewed. It is recommended that further studies be undertaken to include students, teachers or even the university authority ( $\mathrm{VC} / \mathrm{Rector} / \mathrm{Deans})$ to gain better insight on the issues relating to academic freedom, as well as to validate findings from this study. In addition, a mixed method should be considered in which questionnaires should also be designed to triangulate the method for better and in-depth findings. On top of that, future studies should also include the effects of the UUCA on academic freedom before (1971) and after (2011) amendments, as well as the role of university autonomy. 
Thus we have to come back to the future. Restriction of freedom is the history of the past.

\section{References}

Che Noraini, Adlina and Hidayah (2013) Ideal vs reality: Evidences From Senior Teachers' Experiences on the Malaysian School-Based Assessment System (SBA) paper presented at Majlis Dekan Conference, 21-23 Sept 2013, CCAC, IIUM

Lim, Kim-Hui \& Har, Wai-Mun (2008, May). The End of Academia? Germany and Malaysia in Comparison. International Education Studies. Retrieved from www.ccsenet.org/journal.html

Matthew W.Finkin \& Robert C.Post, (2009), For the Common Good 81, Yale University Press, New Haven, p 72

Shils, E. (1995), Academic Freedom and Permanent Tenure. Minerva 33, p 7

The Association of American Colleges and Universities (AAC\&U) (2006, January 6),Board of Directors' Statement on Academic Freedom and Educational Responsibility, p 19

Turner, John (1998), The Price of Freedom. In Academic Freedom and

Responsibility, ed. Malcolm The Sun, November 01, 2011, ( p 01).

UNESCO Volume 1 Resolutions. Record of the General Conference, Twentyninth Session, 21 October to November 1997, Paris: Unesco, 1998, pp 21- 22

Wan A.Manan (2000), Academia Freedom: Ethical Implications and Civic Responsibilities. In Guy Neave (ed.): The Universities Responsibilities to Society. Oxford: Elsevier Science Ltd.

Wan A.Manan (2005), Envisioning World Class Universities in Malaysia: Can We Instil Research, Academic Freedom \& Democratic DecisionMaking? Tertiary Education Main Policies, Challenges \& Opportunities, Quality \& Accreditation \& World Class Universities. Kuala Lumpur. Pusat Penerbitan Universiti (UPENA)

White, L. (2000), Academic Tenure: Its Historical And Legal Meanings In The United States And Its Relationship To The Compensation Of Medical School Faculty Members. Saint LouisUniversity Law Journal 44, p 60 